\title{
CONHECIMENTOS SOBRE FORMAS DE PREVENÇÃO E CONTÁGIO DE ISTS ENTRE ESTUDANTES MATRICULADOS EM ESCOLAS ESTADUAIS DA CIDADE DE MACAPÁ, AMAZÔNIA, BRASIL
}

\section{ARTIGO ORIGINAL}

SALVIANO, Ana Laura Góes ${ }^{1}$

SANTANA, Giovanna Rocha ${ }^{2}$

DIAS, Claudio Alberto Gellis de Mattos ${ }^{3}$

ARAÚJO, Maria Helena Mendonça de ${ }^{4}$

OLIVEIRA, Euzébio de ${ }^{5}$

DENDASCK, Carla Viana ${ }^{6}$

\footnotetext{
${ }^{1}$ Residente em Clínica Médica (HOSPITAL OPHIR LOYLA), Belém, PA.

${ }^{2}$ Residente em Clínica Médica (HOSPITAL UNIVERSITÁRIO DE SERGIPE), Aracajú, SE.
}

${ }^{3}$ Doutor em Teoria e Pesquisa do Comportamento (UFPA). Professor e Pesquisador no Instituto Federal do Amapá (IFAP), campus Macapá, AP. Professor e Pesquisador no Programa de Pós-Graduação em Educação Profissional e Tecnológica (ProfEPT), IFAP, campus Santana, AP.

${ }^{4}$ Mestra em Ensino e ciências da Saúde. Professora e pesquisadora na Universidade Federal do Amapá (UNIFAP), campus Macapá, AP.

${ }^{5}$ Doutor em Teoria e Pesquisa do Comportamento (UFPA). Professor e Pesquisador na Universidade Federal do Pará (UFPA), Campus Castanhal, PA.

6 Doutora em Psicanálise (SEMINÁRIO INTERNACIONAL DE TEOLOGIA). Pesquisadora do Centro de Pesquisas e Estudos Avançados (CEPA). Doutoranda em Comunicação e Semiótica (PUC SP). 
SANTOS, Bruno Rodrigues dos ${ }^{7}$

FECURY, Amanda Alves ${ }^{8}$

SALVIANO, Ana Laura Góes. Et al. Conhecimentos sobre formas de prevenção e contágio de ISTs entre estudantes matriculados em Escolas Estaduais da Cidade de Macapá, Amazônia, Brasil. Revista Científica Multidisciplinar Núcleo do Conhecimento. Ano 05, Ed. 12, Vol. 10, pp. 05-16. Dezembro de 2020. ISSN: 24480959, Link de acesso: https://www.nucleodoconhecimento.com.br/saude/prevencaoe-contagio

\section{RESUMO}

A sexualidade passou a ser vista como um âmbito positivo da atuação humana, nesse contexto, passou-se a valorizar a educação sexual, levantando discussões sobre sua importância. O objetivo deste artigo foi analisar conhecimentos sobre formas de contágio e prevenção de IST. Este estudo foi realizado em 03 escolas estaduais de nível fundamental e médio. A amostra foi constituída de 287 alunos regularmente matriculados nas referidas escolas abrangendo do $8^{\circ}$ ano/ $7 a$ série do ensino fundamental até $03^{\circ}$ ano do ensino médio. Dados acerca do gênero, idade, estado civil, escolaridade e outros foram levantados nesta pesquisa. A maior parte dos participantes já teve contato com o termo IST; contudo, ainda possui crenças sobre suas formas de transmissão. Existe a necessidade de abordar a sexualidade com um aspecto mais natural e positivo da vida humana, proporcionando a livre discussão de normas e padrões de comportamento e o debate das atitudes.

7 Doutor em Teoria e Pesquisa do Comportamento (UFPA). Professor e Pesquisador na Universidade Federal do Pará (UFPA), Campus Belém, PA.

${ }^{8}$ Doutora em Doenças Tropicais (UFPA). Professora e pesquisadora na Universidade Federal do Amapá (UNIFAP), campus Macapá. Professora e pesquisadora no Programa de Pós-Graduação em Ciências da Saúde (UFPA). Pró-Reitora de Pesquisa e Pós-Graduação na Universidade Federal do Amapá (UNIFAP). 
Palavras-chave: IST, AIDS, adolescência, sexualidade.

\section{INTRODUÇÃO}

Não há um padrão universal que defina a faixa etária da adolescência e jovens adultos e, no que tange a adolescência para o Estatuto da Criança e do Adolescente, esta vai dos 12 aos 18 anos. Para o Ministério da Saúde e OMS vai dos 10 aos 19 anos completos, além de adotar a faixa dos 15 aos 24 anos como juventude (BRASIL, 2012; WHO, 2016) A Organização Mundial da Saúde (OMS) define jovens adolescentes aquela faixa etária compreendida entre 15 e 19 anos e jovens adultos como 20 a 24 anos, ou seja, essas faixas etárias em conjunto compreendem a juventude (UNFPA, 2010).

Segundo o censo, adolescentes e jovens de 15 a 29 anos correspondem a 51,3 milhões, ou seja, 1/4 da população total, o que faz com que o Brasil seja um país de população relativamente jovem (IBGE, 2014).

A sexualidade perpassou por diversos sentidos durante a história, desde uma ampla liberdade vivenciada na Grécia e em Roma (onde se buscava apenas o prazer, sem regras ou limites, tanto em busca da reprodução quanto do amor) até a ascensão do cristianismo, quando houve uma enorme pressão/coerção da igreja católica sobre o prazer ser algo extremamente pecaminoso e o sexo praticado somente com âmbitos reprodutivos (MAROLA et al., 2011).

A sexualidade passou a ser vista como um âmbito positivo da atuação humana, com sexo, identidade e papel de gênero, orientação sexual, erotismo, prazer, intimidade e reprodução. Nesse contexto, passou-se a valorizar a educação sexual e não a enxergar como um problema, levantando discussões e argumentações sobre sua importância em meio ao aspecto histórico e cultural das determinadas sociedades (MAROLA et al., 2011).

A OMS prevê direitos sexuais de acordo com os direitos humanos reconhecidos por leis e documentos internacionais. Estes proíbem qualquer forma de coerção, violência 
ou discriminação; além de direitos para todos. O que também se aplica a adolescentes pois, durante essa faixa etária, geralmente, ocorre o início da vida sexual e estes jovens estão expostos a todos fatores positivos e negativos desse processo(MAROLA et al., 2011).

A adolescência é um período bastante conturbado, pois é nela que o indivíduo busca sua identidade, liberdade e autonomia, para que possa se afirmar no meio em que vive como sujeito. Esse processo envolve primariamente mudanças biológicas (hormonais e corporais) que influenciam e se misturam a modificações psicológicas e comportamentais, tudo isso é influenciado pela convivência com a família, amigos, educadores e outros indivíduos inseridos nas relações próximas (BESERRA et al., 2008).

Durante esse processo de autoafirmação o adolescente também busca se impor na sociedade e uma maneira de se fazer isso é o sexo. Deste modo é nessa fase da vida que, geralmente, ocorre o início da vida sexual (BESERRA et al., 2008) e é quando a sexualidade fica mais evidente, pois devido as transformações biopsicossociais pelas quais a vida do adolescente perpassa, esse é um momento de muita curiosidade e de descobertas. Dessa maneira os jovens buscam novas experiências, principalmente as sexuais (CARLETO et al., 2010).

O ingresso na vida sexual, em muitos casos pode ocorrer precocemente, entre os 11 e 15 anos (BESERRA et al., 2008). Em um estudo com universitários recém-ingressos (ARAUJO et al., 2012) a maioria das primeiras relações sexuais ocorreu entre os 14 e 17 anos (72,1\%), sendo que a menor idade detectada foi de 10 anos e a maior foi de 20 anos. No entanto, essa precocidade não vem acompanhada de responsabilidade social, que está ocorrendo na vida dos jovens cada vez mais tarde e por este motivo podemos encontrar comportamentos e atitudes, típicas de adolescentes em faixas etárias superiores aos 19 anos preconizados pela OMS (BRÊTAS et al., 2009). Por esse motivo ocorre o aumento da ocorrência de gravidez na adolescência e o contágio por infecções sexualmente transmissíveis (ISTs) ou ambos (BESERRA et al., 2008). 
O início precoce da vida sexual é, particularmente, interessante principalmente para os garotos, pois este pode ser considerado um sinal de masculinidade. $O$ adolescente do sexo masculino também se impõe mais dentro de uma relação de casal, por exemplo, o que faz com que dependendo da vontade dele faça-se o uso do preservativo ou realize-se um ou outro tipo de prática sexual (CAMARGO e FERRARI, 2009). Isso pode ser evidenciado pela crescente incidência do vírus do HIV entre mulheres adolescentes (OLIVEIRA et al., 2009; ALVES et al., 2019).

A magnitude do problema entre essas jovens é maior do que se pensa, pois apesar de muitas delas trem o conhecimento necessário para o uso do preservativo elas tem dificuldades em negociar essa prática com o parceiro. Em estudo realizado onde 104 adolescentes que faziam o uso da pílula anticoncepcional, apenas $40 \%$ delas utilizavam o preservativo em todas as relações sexuais (OLIVEIRA et al., 2009).

A ocorrência de ISTs em meninos de 13 anos demonstra como eles estão ingressando cedo na pratica sexual e por esse motivo o adolescente deve ser orientado desde cedo sobre formas de contágio e prevenção de ISTs. Isso deve ser feito por meio de diálogo franco e aberto, onde seja permitido que o jovem se expresse e faça seus questionamentos (BESERRA et al., 2008).

Essas informações deveriam ser primariamente concedidas pela família através de conversas onde os pais pudessem esclarecer as dúvidas de seus filhos e orientá-los da melhor maneira possível. No entanto, quando os pais evitam o assunto esses jovens procuram informações em outros locais, como a escola. Sendo que, muitas vezes os professores e outros profissionais envolvidos no processo educacional não estão preparados para lidar com isso. Isso faz com que o adolescente não consiga as informações adequadas e acabe permanecendo desprotegido (BESERRA et al., 2008).

Além disso, um estudo feito em Rio Branco no Acre com estudantes de ensino médio verificou que a maior fonte de informação desses jovens eram seus próprios amigos. Estes, provavelmente, igualmente desprovidos de maturidade e conhecimento 
suficiente para poder se expressar sobre algo tão sério e importante (CARLETO et al., 2010).

Em 2010, Carleto et al. fizeram um trabalho com 499 adolescentes em Cuiabá no Estado do Mato Grosso, onde indagaram sobre as formas de contágio de ISTs. Foi considerado que tinha conhecimento adequado quem selecionou: transar sem camisinha, sexo oral, anal e/ou vaginal sem proteção, compartilhar seringa e agulha para injetar droga. Desse total, apenas $4,62 \%$ conseguiram acertar todas.

Um reflexo disso é a alta incidência de HIV/aids no mundo inteiro entre adolescentes - cerca de 430.000 (UNAIDS, 2019). No Brasil, em 2007, foram notificados 10.337 casos da doença entre jovens de 13 a 19 anos (CARLETO et al., 2010). Em uma pesquisa com 74 adolescentes (estudantes do ensino médio) de uma escola da rede estadual em Cruz Alta no Rio Grande do Sul, apenas 3 deles não portavam nenhuma IST (BUENO et al., 2012).

O objetivo deste artigo foi analisar conhecimentos sobre formas de contágio e prevenção de IST dos estudantes de escolas estaduais do ensino fundamental e médio do Estado do Amapá, regularmente matriculados na zona urbana da capital, Macapá.

\section{MATERIAIS E MÉTODOS}

Este estudo foi realizado em 03 escolas estaduais de nível fundamental e médio. A amostra foi constituída de 287 alunos regularmente matriculados nas referidas escolas abrangendo do $8^{\circ}$ ano/ 7a série do ensino fundamental até o $3^{\circ}$ ano do ensino médio.

Foi utilizada a relação $80 \mathrm{ano} / 7$ a série e $90 \mathrm{ano} / 8$ a série porque algumas escolas ainda não implementaram o Projeto de lei n 144/2005 aprovado pelo Senado em janeiro de 2006 e sancionado em fevereiro de 2006 pelo Presidente da República a partir da lei $n^{\circ} 11.274$ (BRASIL, 2006) que regulamenta o Ensino Fundamental de 9 anos com matrícula obrigatória a partir dos 6 (seis) anos de idade. A legislação prevê 
que sua medida deveria ser implantada até 2010 pelos Municípios, Estados e Distrito Federal.

A população do estudo foi constituída por adolescentes e adultos jovens (de 15 a 24 anos) dos sexos masculino e feminino, regularmente matriculados em escolas no município de Macapá- AP, que cursem ensino fundamental ou médio em escolas públicas estaduais. A amostra utilizada foi definida através de cálculo amostral.

A partir de tabelas disponibilizadas pela Secretaria de Educação do Estado do Amapá, conforme a quantidade de alunos do Ensino Fundamental matriculados regularmente no ano de 2017 e dos alunos do Ensino Médio matriculados em 2018. O erro amostral utilizado foi de $5 \%$, nível de confiança de $95 \%$. Para o cálculo dos alunos de escolas públicas estaduais do ensino fundamental 80 ano/ 7a série e 90 ano/ 8 a série e ensino médio regular foram utilizados os valores do total de alunos das escolas públicas do Estado do Amapá em áreas urbanas relacionado aos valores das escolas de Macapá que pertencem à área urbana e que comportam as séries descritas acima.

Foram incluídos no estudo indivíduos do sexo masculino e feminino, que residam no Estado do Amapá e que estejam no ensino fundamental ou médio. Os mesmos autorizaram a participação voluntária na pesquisa mediante a assinatura do Termo de Consentimento Livre e Esclarecido (TCLE) e, para os menores de 18 anos, assinatura do responsável legal (TALE - Termo de Assentimento Livre e Esclarecido). Serão excluídos do estudo os indivíduos que estejam fora dos critérios estabelecidos, que os responsáveis não autorizem a participação e que não estejam matriculados na rede regular de ensino.

Para cada participante foi entregue um questionário principal contendo dois blocos: $\mathrm{A}$ e $B$. As perguntas do bloco $A$ foram referentes às informações sociodemográficas de cada estudante. São 12 perguntas nas quais foram abordados os seguintes temas: gênero, idade, estado conjugal, grau de escolaridade, curso mais elevado que o chefe de sua família completou, raça, religião, situação de trabalho atual e possíveis itens que existem em suas casas. 
Para a coleta de dados foi realizada uma adaptação do questionário utilizado pelo Ministério da Saúde para a pesquisa de Conhecimentos, Atitudes e Praticas na População Brasileira, feita em 2008 (BRASIL, 2011).

As escolas contatadas e que concordaram inicialmente em participar do estudo apresentaram termo de anuência. Foi explicado a todos os alunos participantes, em linguagem clara e direta, os objetivos, benefícios e possíveis malefícios oriundos da pesquisa, além de que houve sigilo absoluto e a privacidade de cada um esteve garantida. Depois disso, ao concordar, o indivíduo assinou o Termo de Consentimento Livre e Esclarecido (TCLE), autorizando a sua participação voluntária. Caso o participante fosse menor de idade seu responsável legal também assinou um Termo de Assentimento Livre e Esclarecido (TALE). O estudo atendeu as considerações éticas dispostas na resolução 466 de 12 de dezembro de 2012 do Conselho Nacional de Saúde e foi submetido à avaliação e aprovado pelo Comitê de Ética em Pesquisa (CAAE 66761617.1.0000.0003), após registro na Plataforma Brasil.

\section{RESULTADOS}

Participaram da pesquisa 287 estudantes, sendo 140 (48,8\%) pertencentes ao gênero feminino e 147 (51,2\%) ao masculino.

Com relação à idade, a maior parte dos estudantes tinha entre 16 e 18 anos. Desses, 75 (26,1\%) possuíam 16 anos; 85 (29,6\%), 17 anos; e 60 (20,9\%), 18 anos.

Na pergunta sobre em qual estado civil eles estavam atualmente, $224(78,1 \%)$ nunca foram casados, 35 (12,2\%) são conviventes (casados ou vivem com companheiro) e $9(3,1 \%)$ são separados, $3(1,0 \%)$ viúvos, e 16 (5,6\%) pessoas não responderam a esse item.

Quanto ao grau de escolaridade desses estudantes, 141 (49,1\%) estão na $1^{\text {a }}$ ou $2^{\mathrm{a}}$ série do Ensino Médio, 79 (27,5 \%) possuem o Ensino Fundamental completo, 44 (15,3\%) têm o Ensino Médio Completo, 5 (1,7\%) estão na $1^{\text {a }}$ a $3^{\text {a }}$ série do Ensino 
Fundamental, $2(0,7 \%)$ estão na $4^{\mathrm{a}}$ a $7^{\mathrm{a}}$ série do Ensino Fundamental e $16(5,7 \%)$ estudantes não responderam a este item.

Na pergunta "Qual o curso mais elevado que o chefe de sua família completou?", 86 $(30,0 \%)$ afirmaram ter sido o Superior Completo, 75 (26,1\%) Ensino Médio completo, $34(11,8 \%) 4^{\mathrm{a}}$ a $7^{\mathrm{a}}$ série do Ensino Fundamental, 25 (8,8\%) Ensino Fundamental completo, 23 (8\%) Superior Incompleto, 20 (6,9\%) 1ํㅡㄹ ou 2ª série do Ensino Médio, 14 (5\%) $1^{\underline{a}}$ a $3^{\mathrm{a}}$ série do Ensino Fundamental, 3 (1\%) são analfabetos e 7 (2,4\%) pessoas não responderam a esse item.

Quando perguntados "Como se classificam em relação a sua cor?", 140 (48,8\%) declararam ser pardos, 49 (17\%) brancos, $46(16 \%)$ pretos, 14 (4,9\%) amarelos, 12 $(4,1 \%)$ indígenas, 14 (4,9\%) não souberam responder qual a sua cor/raça e 12 (4,3\%) estudantes deixaram em branco este item.

Perguntados sobre "Você se considera religioso?", 211 (73,5\%) responderam com 'Sim" enquanto que $66(23,0 \%)$ responderam com "Não". Apenas 10 (3,5\%) pessoas não responderam a este item. Com relação a pergunta "Qual a sua religião?", 107 (37,3\% \%) afirmaram ser Católicos, 105 (36,6\%) Evangélicos, 2 (0,7\%) Ubanda/Candombé e $1(0,4 \%)$ Espírita. 72 (25\%) pessoas não responderam a este item.

Na pergunta "Qual a sua situação de emprego atual?", 226 (78,8\%) afirmaram não trabalhar atualmente, $13(4,5 \%)$ são empregados com carteira assinada, $12(4,3 \%)$ trabalham sem carteira assinada, 10 (3,5\%) trabalham por conta própria, 7 (2,4\%) são empregadores, 6 (2 \%) são servidores públicos e 13 (4,5\%) estudantes não responderam a este item.

Quando perguntados "Qual a principal razão de você não estar trabalhando atualmente?", 142 (49,5\%) confirmaram não estar trabalhando devido a estudos/treinamentos, $56(19,6 \%)$ procuraram, mas não conseguiram encontrar trabalho, 3 (1\%) são donas de casa/cuidam da família, 1 (0,3\%) é aposentado, 1 
$(0,3 \%)$ é doente, $1(0,3 \%)$ (possui trabalho não remunerado), $83(29 \%)$ estudantes não responderam este item.

As informações sociodemográficas sobre os itens que os entrevistados possuem nos domicílios. A maioria dos estudantes possui televisor (275/287), não tem rádio (138/287), tem banheiro (272/287), automóvel (164/287), sem funcionárias mensalistas (205/287), tem máquina de lavar (258/287), DVD ou vídeo cassete (180/287), geladeira (264/287) e freezer (162/287).

O bloco $\mathrm{B}$ refere-se às formas de transmissão de algumas doenças. Com relação à pergunta "Qual ou quais das doenças descritas na cartela uma pessoa pode ser infectada ao ser picado por um inseto, como por exemplo, um mosquito ou pernilongo?", $42(14,6 \%)$ alunos marcaram que ISTs (AIDS, sífilis, hepatite e gonorreia) podem ser transmitidas por picada de insetos; 250 (87,1\%) alunos marcaram "Dengue"; 168 (58,5\%), a opção "Malária"; 9 (3,1\%), a opção "Nenhuma destas"; $10(3,4 \%)$ estudantes deixaram o questionamento vazio.

Quanto à pergunta "Qual ou quais das doenças descritas na cartela uma pessoa pode ser infectada ao usar banheiros públicos?" 50 (17,4\%) alunos marcaram a opção "AIDS", 68 (23,7\%), a opção "sífilis", 50 (17,4\%) a opção "hepatite", 8 (2,7\%), a opção "dengue", 10 (3,8\%) a opção "malária", 134 (46,6\%), a opção "gonorreia", 38 (13,2\%), a opção "nenhuma destas" e 27 (9,4\%) alunos não marcaram.

A respeito do questionamento "Qual ou quais das doenças descritas na cartela uma pessoa pode ser infectada ao compartilhar seringa ou agulha com outras pessoas?" $230(80,13 \%)$ estudantes assinalaram o item "aids", 57 (19,86\%), o item "sífilis", 65 (22,64\%), o item "hepatite", 8 (2,78\%), o item "dengue", 15 (5,22\%), o item "malária", 27 (9,40\%), o item "gonorreia", 8 (2,78\%), o item "nenhuma destas" e 18 (6,27\%) não assinalaram o questionamento.

Na pergunta "Qual ou quais doenças descritas na cartela uma pessoa pode ser infectada ao não usar preservativos em relações sexuais?" 256 (89,19\%) alunos marcaram o item "Aids", 138 (48,08\%), o item "Sífilis", 16 (5,57\%), o item "Hepatite", 5 
(1,74\%), o item "Dengue", 2 (0,69\%), o item "Malária”, 117 (40,76\%), o item “Gonorreia”, 4 (1,39\%), o item "Nenhuma destas" e 13 (4,52\%) não marcaram.

Com relação à pergunta "Para qual ou quais das doenças descritas na cartela existe cura?" 14 (4,87\%) estudantes assinalaram a opção "Aids", 51 (17,77\%), a opção "Sífilis", 124 (43,20\%), a opção "Hepatite", 219 (76,30\%), a opção "Dengue", 196 (58,88\%), a opção “Malária”, 112 (39,02\%), a opção “Gonorreia”, 10 (3,48\%), a opção "Nenhuma destas" e 15 (5,22\%) deixaram o questionamento vazio.

A partir do questionamento, os alunos deveriam marcar se concordavam ou discordavam com a assertiva proposta. Na assertiva 18 "O risco de transmissão do vírus da AIDS pode ser reduzido se uma pessoa tiver relações sexuais somente com o parceiro fiel e não infectado", 155 (54,0\%) alunos marcaram a opção "Concorda"; 93(32,4\%), a opção "Discorda"; 28 (9,8\%), a opção "não sabe" e 11 (3,8\%) deixaram a assertiva vazia.

A respeito da assertiva "Uma pessoa com aparência saudável pode estar infectada pelo vírus da AIDS", 220 (76,7\%) estudantes marcaram o item "Concorda"; 26 (9,0\%), o item "Discorda"; 30 (10,5\%), o item "Não sabe" e 11 (3,8\%) não marcaram nenhum item.

Quanto à assertiva "Usar preservativo é a melhor maneira de evitar que o vírus da aids seja transmitido durante a relação sexual", 258 (90,0\%) estudantes assinalaram o item "Concorda"; 11(3,8\%), o item "Discorda"; 9(3,1\%), o item "Não sabe" e 9 (3,1\%) deixaram a assertiva vazia.

Com relação à assertiva "Uma pessoa pode ser infectada com o vírus da aids compartilhando talheres, copos ou refeições", 68 (23,7\%) marcaram a opção "Concorda"; 160 (55,8\%), a opção "Discorda"; 50 (17,4\%), a opção "Não sabe" e 9 $(3,1 \%)$ deixaram a assertiva em branco.

Acerca da assertiva "Uma mulher grávida que esteja com o vírus da aids e recebe um tratamento específico durante a gravidez e no momento do parto diminui o risco de passar o vírus da aids para o seu filho", 142 (49,5\%) assinalaram o item "Concorda"; 
60 (20,9\%), o item "Discorda"; 77 (26,8\%), o item "Não sabe" e 8 (2,8\%) não marcaram nenhum item.

\section{DISCUSSÃO}

Dos 287 estudantes que responderam a esta pesquisa, a maioria pertence ao gênero masculino (51,2\%). Estudo similar, realizado Brêtas et al. (2009), também verificou predomínio de homens. Esse discreto predomínio do gênero masculino entre estudantes adolescentes do ensino médio visto em ambos os estudos pode estar relacionado ao também predomínio de tal gênero na faixa etária escolar de 13 a 17 anos (IBGE, 2015).

A maioria dos estudantes relatou ter 17 anos e a média de idade foi de 16,7 anos. De acordo com dados do IBGE 2015, os alunos matriculados em escolas públicas têm faixa etária semelhante à encontrada nesse estudo, entre 15 a 17 anos de idade. Observa-se que o número de jovens matriculados no ensino médio nessa faixa etária era de aproximadamente $80 \%$ do total de jovens (BRASIL, 2013a).

Em relação ao estado civil dos entrevistados, a maioria declarou-se solteiro $(78,1 \%)$, corroborando com os achados em outro estudo (ARAGÃO et al., 2011). Esses dados podem estar relacionados com a faixa etária ainda jovem dos entrevistados, que tende a ter maioria de solteiros (IBGE, 2016).

Quanto ao grau de escolaridade dos entrevistados, predominaram os que estavam cursando o ensino médio. Um contraponto encontrado no questionário aplicado está na interrogativa - "Qual o seu grau de escolaridade? ", pois os estudantes entrevistados observaram a ausência de um item que contemplasse os que estão no 3 o ano do ensino médio, sendo que estes foram orientados a marcar a opção que mais se aproximasse da sua série de ensino. O predomínio de estudantes cursando o ensino médio deve-se ao fato de o público alvo desta pesquisa encontrar-se na faixa etária de 14 aos 21 anos de idade (IBGE, 2015). 
Um dos itens trata sobre o nível de escolaridade dos pais dos estudantes. $\mathrm{Na}$ distribuição desses níveis de escolaridade houve um discreto predomínio de pais que possuem nível superior completo (30,7\%). Uma pesquisa que avalia o conhecimento sobre sexualidade de 1545 estudantes, encontrou distribuição semelhante. Diante dessas informações deve-se atentar para o aumento do número de anos de escolaridade dos trabalhadores brasileiros que, segundo dados divulgados pela Fundação Getúlio Vargas, em 2017, houve um aumento médio de 68\% em anos de escolaridade para as camadas mais carentes da população e um aumento de $10 \%$ para as camadas mais ricas entre os anos de 2003 e 2014 (CARVALHO et al., 2017; PINTO, 2017).

Um outro item desta pesquisa indagava sobre a cor/raça dos estudantes entrevistados. Destes, a maioria declarou-se parda (48,8\%). Esse achado é compatível com as últimas pesquisas divulgadas pelo IBGE onde mostram que a maior parte dos brasileiros se autodeclaram pardos (46,8\%). É possível perceber nessa informação que os dados da pesquisa acompanharam mudança de predomínio de raça/cor evidenciada desde 2014 onde foi observado o aumento do número de brasileiros que se declaravam pretos e pardos promovendo uma queda dos que se autodeclaravam brancos (IBGE, 2014; 2017).

Quanto a indagação de "se possuíam religião", 73,5\% dos estudantes responderam "sim", enquanto 23,0\% deles responderam "não", sendo que a religião atual da maioria $(37,3 \%)$ foi o catolicismo, seguido da religião evangélica (36,6\%). O crescente número dos que declaram não possuir religião pode ser explicado pelo fato de tanto a religião católica quanto a evangélica persistirem em criticar a desvinculação da atividade sexual ao casamento ou fecundidade apesar de reconhecerem as profundas mudanças vivenciadas nas esferas de religião e da sexualidade. É possível perceber que as igrejas tendem a usar instrumentos punitivos para assegurar que seus jovens não iniciem sua vida sexual pré-marital (como a perda de prestigio ou de liderança dentro da igreja) podendo afastar, dessa forma os adolescentes de suas religiões (COUTINHO e RIBEIRO, 2014). 
Nos itens que questionaram sobre qual o emprego atual do entrevistado e qual o principal motivo para este não estar trabalhando atualmente pode-se perceber uma clara dificuldade de resposta por parte dos estudantes, pois os mesmos marcaram opções incompatíveis com sua faixa etária e grau de escolaridade. Esse tipo de dificuldade é justificado pelo fato de a existência de uma lista pré-determinada de opções nas entrevistas em forma de questionários com respostas "fechadas", pode criar a tendência em se escolher uma ou mais categorias (opções) sem que realmente o entrevistado reflita sobre o assunto (JUNIOR, 2005).

Com relação ao segundo bloco de perguntas, dos 287 alunos entrevistados, apenas 14,63\% (Gráfico 11) marcaram que ISTs (aids, sífilis, hepatite e gonorreia) podem ser transmitidas por picada de insetos, o que significa que a maioria $(85,36 \%)$, distancia o termo "ISTs" de doenças transmitidas por mosquitos. Em um estrudo foi constatado que a maior parte dos estudantes sabia definir adequadamente IST como doença transmitida por relação sexual (GENZ et al., 2017). Este resultado é possível porque desde a década de 90 houve propostas de inovação na educação básica brasileira, a partir da introdução de temas transversais, como orientação sexual. (SILVA, 2008).

Contudo, na análise do questionamento acerca da transmissibilidade de determinadas ISTs ao utilizar banheiro público, 46,68\% marcaram a opção "gonorreia", mostrando que quase metade dos alunos, apesar do conhecimento conceitual do termo "IST", possui crenças acerca das formas de contágio de determinadas infecções sexualmente transmissíveis. Brêtas et al. (2009), constatou isso em seu estudo, no qual grande porcentagem dos adolescentes não conhecia qualquer forma de transmissão das ISTs. A presença de alguns mitos pode ser justificada porque, segundo Beserra et al. (2008), a informação sobre relações sexuais é na maioria das vezes discutida entre os próprios jovens; e tais informações são geralmente trazidas pela mídia e interpretadas de forma errônea.

Ainda sobre modos de infecção, deve-se atentar ao fato de que grande parte dos alunos $(80,13 \%)$ assinalou que AIDS pode ser transmitida ao compartilhar seringa ou agulha com outras pessoas, mostrando que muitos conhecem outros modos. A maioria dos adolescentes entrevistados conhecia tal forma de transmissão (NADER 
et al., 2009). A partir desses dados depreende-se, portanto, que os adolescentes apesar de algum conhecimento, ainda possuem dúvidas e incertezas acerca do tema (AMORIM e MAIA, 2012).

Sobre a possibilidade de infecção a partir do não uso de preservativos, ocorreram discrepâncias no conhecimento das ISTs listadas, quase $90 \%$ dos alunos responderam AIDS, porém menos da metade dos alunos marcaram sífilis, gonorreia e hepatite, mostrando que muitos desconhecem outras infecções sexualmente transmissíveis além da AIDS. Em escolas públicas de Rio Claro, SP, menos de 10\% dos alunos citaram hepatite, pouco mais de $20 \%$ citaram gonorreia e sífilis (SILVA, 2015). Esse resultado pode ser justificado pelo fato de que desde a década de 80 a AIDS é vista como uma epidemia no Brasil e, nesse contexto, as políticas públicas acerca dessa IST são maiores (BRASIL, 2015).

Quando questionados acerca da cura de determinadas doenças, quase $40 \%$ desconheciam a cura de gonorreia, mais de $40 \%$ classificaram hepatite como curável e apenas 4,87\% marcaram AIDS, mostrando que o conhecimento dentre as ISTs é variável entre os alunos, predominando as certezas sobre a AIDS. Brêtas et al. (2009), teve um resultado diferente, seus estudantes conheciam principalmente a gonorreia como IST curável, seguida de sífilis e herpes. A diferença de conhecimento entre a população do estudo de Brêtas et al. (2009) e esta pesquisa, pode ser justificada pelo fato de que na região Norte o acesso à informação pode ser mais escasso que quando comparado ao Sudeste do país (BRASIL, 2014).

Dois questionamentos relacionam-se na pesquisa (gráficos 16 e 18), pois avaliam o risco de transmissão do vírus da AIDS a partir de um parceiro fiel e do uso de preservativos. Um pouco mais da metade dos alunos (54\%) concorda que o parceiro fiel e não infectado diminui os riscos de infecção e quase 90\% (258) dos alunos concorda que a camisinha é a melhor forma de prevenir que o vírus seja transmitido na relação sexual. Esses resultados são confrontados em um estudo, em que mais da metade $(66 \%)$ dos adolescentes entrevistados não utilizavam preservativos, apesar de terem o conhecimento sobre as formas de transmissão, justificando por: "já conhecerem o parceiro", "ser casado", "parceiro fixo", ou seja, apesar do 
conhecimento, ainda se submetiam ao risco em virtude de fatores relacionados ao parceiro (CANO et al., 2007).

Esta pesquisa mostrou que $23,34 \%$ dos alunos desconhecem que uma pessoa com aparência saudável possa estar infectada pelo vírus HIV. No Brasil estima-se que 600 mil pessoas vivam com o vírus ou já tenham desenvolvido AIDS (SANTOS et al., 2012). Um estudo obteve resultado semelhante $(26,8 \%)$, onde os entrevistados não sabiam se uma pessoa infectada tinha sintomas aparentes. Portanto, percebe-se que o conhecimento sobre o tema entre os jovens ainda é escasso quando se pesquisa a fundo acerca dos estigmas sociais relacionados à AIDS, sendo necessário o investimento em conteúdos de qualidade sobre o tema (NADER et al., 2009).

Outro questionamento foi com relação à transmissão a partir de talheres, copos e refeições. Mais de $40 \%$ concordavam com esse risco ou não sabiam o que responder (gráfico 19). Outra pesquisa demonstrou que $20 \%$ dos entrevistados relataram que essas são possíveis fontes de contaminação (NADER et al., 2009). O fato é que não há risco real de infecção por contato de saliva, haja vista ela contém proteínas e baixa quantidade de sal capazes de neutralizar o vírus (FREITAS et al., 2017).

Outro ponto importante foi sobre a possibilidade de uma mulher em tratamento específico durante a gravidez e o parto diminuir as chances de transmitir o vírus HIV para seu filho, cerca de $47 \%$ discordaram ou não sabiam responder (gráfico 20 ). Jordão et al. (2016), obteve resultado semelhante em pesquisa realizada com gestantes, nas quais $45,8 \%$ desconheciam a possibilidade de tomar uma medicação capaz de evitar a transmissão do vírus da AIDS de uma grávida infectada para o seu bebê. Nesse contexto, percebe-se que existe declínio de conhecimento da população jovem e adulta quando se diz respeito à transmissão vertical (JORDÃO et al., 2016).

\section{CONCLUSÃO}

A maior parte dos participantes já teve contato com o termo IST; contudo, ainda possui crenças sobre suas formas de transmissão. Esses resultados mostram a importância de se investir na educação sexual dos adolescentes, pois eles são o principal alvo 
etário de vulnerabilidade das ISTs. Tal ensino deve ser orquestrado ao nível de compreensão destes jovens, conscientizando-os do direito de escolha com o cuidado de sua saúde.

Esta informação pode ser comprovada, pois a partir da década de 80 muitos investimentos acerca de políticas públicas e mídias sociais sobre a AIDS propiciaram aumento do conhecimento com relação a outras ISTs. Muitos ainda desconhecem o mesmo risco para outras infecções sexualmente transmissíveis, como sífilis, hepatite e gonorreia. Evidenciando a necessidade de abordar a sexualidade com um aspecto mais natural e positivo da vida humana, proporcionando a livre discussão de normas e padrões de comportamento e o debate das atitudes das pessoas em relação ao sexo e à própria sexualidade, enfatizando discussões sobre formas de transmissão e contágio de ISTs.

\section{REFERÊNCIAS BIBLIOGRÁFICAS}

ALVES, G. C. et al. Frequency of AIDS cases Identified in Brazil between 2012 and 2016. Revista Científica Multidisciplinar Núcleo do Conhecimento, v. 03, p. 3744, 2019.

AMORIM, R. M.; MAIA, A. C. B. Sexualidade na adolescência: dúvidas de alunos de uma escola pública. Revista Ibero-Americana de Estudos em Educação, v. 07, n. 04, p. 95 - 106, 2012.

ARAGÃO, J. C. S.; LOPES, C. S.; BASTOS, F. I. Comportamento Sexual de Estudantes de um Curso de Medicina do Rio de Janeiro. Revista Brasileira de Educação Médica, v. 35, n. 03, p. 334-340, 2011.

ARAUJO, D. S. et al. Práticas de sexo seguro e prevenção de DST/AIDS: Conhecimento de jovens recém-ingressos em uma instituição de ensino superior. Revista de Enfermagem da UFPI, v. 01, n. 01, p. 56-63, 2012. 
BESERRA, E. P. et al. Adolescência e Vulnerabilidade às Doenças Sexualmente Transmissíveis: Uma Pesquisa Documental. DST - Jornal Brasileiro de Doenças Sexualmente Transmissíveis, v. 20, n. 01, p. 32-35, 2008.

BRASIL. LEI № 11.274, DE 6 DE FEVEREIRO DE 2006. Brasilia DF: Presidência da República Casa Civil. LEI № 11.2742006.

- Pesquisa de Conhecimentos, Atitudes e Práticas na População Brasileira (Série G. Estatística e Informação em Saúde). Brasília: Ministério da saúde. : 126 p. 2011.

ESTATUTO DA CRIANÇA E DO ADOLESCENTE. Brasilia DF: Edições Câmara, 2012. 207.

\section{EDUCAÇÃO BRASILEIRA: INDICADORES E DESAFIOS DOCUMENTO}

DE CONSULTA. Brasília DF: MINISTÉRIO DA EDUCAÇÃO, 2013a.

- Relatório educação para todos no Brasil 2000-2015. Brasília

DF, 2014. Disponível em: <

http://portal.mec.gov.br/index.php?option=com_docman\&view=download\&alias=1577 4-ept-relatorio-06062014\&category_slug=junho-2014-pdf\&Itemid=30192 >. Acesso em: 10 de setembro 2018.

Boletim Epidemiológico HIV/AIDS. Brasília DF: Ministério da Saúde: 96 p. 2015

BRÊTAS, J. R. D. S. et al. Conhecimento sobre DST/AIDS por estudantes e adolescentes. Rev. esc. enferm. USP v. 43, n. 03, p. 551-557, 2009.

BUENO, I. et al. Doenças sexualmente transmissíveis: informação e prevenção na adolescência. Ciência, reflexividade e incertezas - XVII Seminário Interinstitucional de ensino, pesquisa e extensão. Cruz Alta RS: UNICRUZ 2012. 
CAMARGO, E. Á. I.; FERRARI, R. A. P. Adolescentes: conhecimentos sobre sexualidade antes e após a participação em oficinas de prevenção. Ciência \& Saúde Coletiva, v. 14, n. 03, p. 937-946, 2009.

CANO, M. A. T. et al. O conhecimento de jovens universitários sobre AIDS e sua prevenção. Revista Eletrônica de Enfermagem, v. 09, n. 03, p. 748 - 758, 2007.

CARLetO, A. P. et al. Conhecimentos e Práticas dos Adolescentes da Capital de Mato Grosso quanto às DST/Aids. DST - J bras Doenças Sex Transm, v. 22, n. 04, p. 206-211, 2010.

CARVALHO, C. P. et al. Conhecimentos sobre sexualidade: Construção e validação de um instrumento de avaliação para adolescentes em contexto escolar. Revista Portuguesa de Educação, v. 30, n. 02, p. 249-274, 2017.

COUTINHO, R. Z.; RIBEIRO, P. M. Religião, religiosidade e iniciação sexual na adolescência e juventude: lições de uma revisão bibliográfica sistemática de mais de meio século de pesquisas. Revista Brasileira de Estudos da População, v. 31, n. 02, p. 333-365, 2014.

FREITAS, R.; CAMPOS, M. J.; ROCHA, M. Rastreio da infeção pelo VIH e riscos de transmissão sexual. Lisboa PT: GAT, 2017. 60 p.

GENZ, N. et al. Doenças Sexualmente transmissíveis: Conhecimento e comportamento sexual de adolescentes. Texto Contexto Enfermagem, v. 26, n. 02, p. 1-12, 2017.

IBGE. Censo 2010. Rio de Janeiro RJ, 2014. Disponível em: < http://www.ibge.gov.br/home >. Acesso em: 29 Dezembro de 2016.

. Pesquisa Nacional de Saúde do Escolar, Amostra 2. Rio de Janeiro RJ, 2015. Disponível em: < http://www.ibge.gov.br/home >. Acesso em: 10 de setembro 2018. 
. Estatísticas do Registro Civil. Rio de Janeiro RJ, 2016. Disponível em: < http://www.ibge.gov.br/home >. Acesso em: 10 de setembro 2018.

. Pesquisa das Características Étnico-raciais da População. Rio de janeiro RJ, 2017. Disponível em: < http://www.ibge.gov.br/home >. Acesso em: 10 de setembro 2018.

JORDÃO, B. A. et al. Conhecimento da gestante sobre o HIV e a transmissão vertical em São José do Rio Preto, São Paulo, Brasil. Revista Brasileira de Pesquisa em Saúde, Vitória, v. 18, n. 02, p. 26-34, 2016.

JUNIOR, P. R. D. O. B. Elicitação de requisitos de software através da utilização de questionários. 2005. 87 (Mestrado). Pós-graduação em Informática, PUC, Rio de Janeiro RJ.

MAROLA, C. A. G.; SANCHES, C. S. M.; CARDOSO, L. M. Formação de conceitos em sexualidade na adolescência e suas influências. Psicologia da Educação, v. 33, n. 02, p. 95-118, 2011.

NADER, S. S. et al. Juventude e AIDS: conhecimento entre os adolescentes de uma escola pública em Canoas, RS. Revista da AMRIGS, v. 53, n. 04, p. 374-381, 2009.

OLIVEIRA, D. C. D. et al. Conhecimentos e Práticas de Adolescentes acerca das DST/HIV/AIDS em duas Escolas Públicas Municipais do Rio de Janeiro. Esc Anna Nery Rev Enferm, v. 13, n. 04, p. 833-841, 2009.

PINTO, I. F. D. A. Educação e desigualdade de renda no Brasil. 2017. 54 (Mestrado). Escola Brasileira de Economia e Finanças, FGV, Rio de Janeiro RJ.

SANTOS, A. T. O. et al. Novos avanços relacionados ao HIV/AIDS. Revista Enfermagem Contemporânea, v. 01, n. 01, p. 80-102, 2012.

SILVA, L. R. G. A política educacional e a orientação sexual nas escolas. Revista Eletrônica de Política e Gestão Educacional, n. 5, 2008. 
SILVA, R. Quando a escola opera na conscientização dos jovens adolescentes no combate às DSTs. Educ. rev. [online], v. 57, p. 221-238, 2015.

UNAIDS. Estatísticas. Brasília DF, 2019. Disponível em: < https://unaids.org.br/estatisticas/ >. Acesso em: 08 setembro 2019.

UNFPA. Direitos da população jovem: Um marco para o desenvolvimento. Brasília DF: UNFPA, 2010. 126p.

WHO. Adolescente Development. 2016. Disponível em: < http://www.who.int/maternal_child_adolescent/topics/adolescence/dev/en/ >. Acesso em: 11 dezembro 2016.

Enviado: Dezembro, 2020.

Aprovado: Dezembro, 2020. 